\section{Weighing the evidence: do Archaean igneous compositions forbid, allow, suggest or require plate tectonics?}

\author{
JEAN-FRANÇOIS MOYEN ${ }^{1}$, OSCAR LAURENT ${ }^{2}$, PETER \\ A CAWOOD $^{3}$, OLIVER NEBEL ${ }^{3}$, FABIO CAPITANIO ${ }^{3}$, \\ CYRIL CHELLE-MICHOU ${ }^{4}$ AND ANDERS MAC CARTHY ${ }^{5}$ \\ ${ }^{1}$ Université Jean Monnet \\ ${ }^{2}$ CNRS-Géosciences Environnement Toulouse \\ ${ }^{3}$ Monash University \\ ${ }^{4}$ ETH Zürich \\ ${ }^{5}$ University of Tasmania \\ Presenting Author: jean.francois.moyen@univ-st-etienne.fr
}

The composition of (Archaean) igneous rocks, from major and trace elements, to an ever-expanding range of isotopic ratios, is commonly used to discuss Earth's tectonic style. More often than not, the findings of such studies are framed in as a binary alternative: did plate tectonics operate (or not) in the Archaean?

This schematic view has outlived its utility and is now actually hindering progress on understanding early Earth dynamics. The composition of igneous rocks reflects, primarily, the nature of the source material (mantle, crust...) and the conditions of melting (deep/shallow, dry/wet...) as well as the subsequent evolution of the magma. There is no direct link between a composition and a tectonic site: any setting that permits decompression melting of the depleted mantle will yield MORB-like magmas, any situation that allows burial of surface material and fluxed melting above it will form arc-like magmas, irrespective of whether this occurs in divergent or convergent plate boundaries, respectively.

Comparison with other planets (Venus), the advances of geophysics and of geodynamic modelling, all suggest that there are many possible modes of planetary dynamics, and that discussing them in terms of "plates" or "non plates" is too simplistic. It also highlights the fact that the debate is largely semantic, and that there is no agreement on the meaning of key terms such as "subduction" or even "plate tectonics". Many of the geological evidences (and in particular the geochemical, including isotopic data), taken as clear markers for "plate tectonics" (or conversely, of its absence) are actually compatible with a large range of global tectonic systems, and cannot provide unique and unambiguous constraints on tectonic setting. Collectively, this suggests that the old question "when did Plate Tectonics begin" is, at the very least, an inappropriate way to frame the debate and cannot be answered without being qualified.

Petrology and geochemistry investigations can answer petrochemical questions of melt evolution. In this context, a profound understanding of Archean petrology in a P-T-X sense provides important constraints on Archean geodynamics. This provides a scientific roadmap to planetary evolution, instead of a hunt for a miracle that never happened.

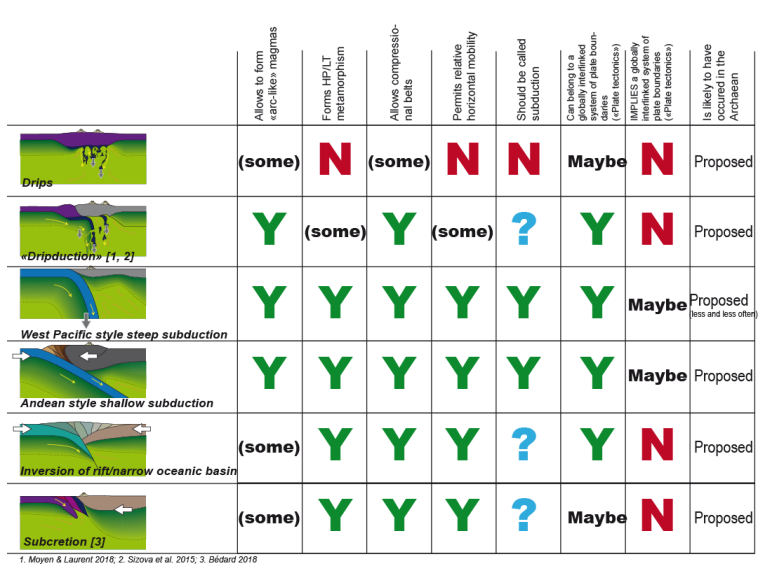

